\title{
SYNTHESIS OF EFFECTIVE IDEAS OF INNOVATIVE PROJECTS DURING THE DEVELOPMENT OF THE EIGHTH TECHNOLOGICAL ORDER
}

\author{
Valery Vladimirovich Glushchenko $1 \square$ (iD) \\ ${ }^{1}$ Doctor of Technical Sciences, Associate Professor, Moscow, Russia
}

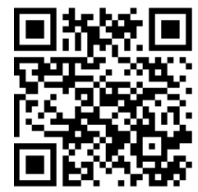

\section{ABSTRACT}

Received 05 September 2021

Accepted 15 October 2021

Published 31 October 2021

\section{CorrespondingAuthor}

Valery Vladimirovich Glushchenko, gluvalery@yandex.ru

\section{DOI 10.29121/IJOEST.v5.i5.2021.238}

Funding: This research received no specific grant from any funding agency in the public, commercial, or not-for-profit sectors.

Copyright: (C) 2021 The Author(s). This is an open access article distributed under the terms of the Creative Commons Attribution License, which permits unrestricted use, distribution, and reproduction in any medium, provided the original author and source are credited.

The subject of the article is the synthesis of ideas of innovative projects during the formation of the eighth technological order (ETO); the object of the article is innovative activity during the ETO; the purpose of the work is to increase the efficiency of the synthesis of innovative ideas during the transition to the ETO; to achieve this goal, the following tasks are solved: research and clarification of the concept and essence of innovative ideas; analysis of factors and methods of synthesis of innovative ideas in the process of development of a new technological order; formation of methods for the analysis of innovative ideas; description of modeling processes and business planning of projects for the implementation of these ideas; scientific methods in the article are: synthesis theory; theory of technological order, modeling theory, expert assessments, heuristic synthesis, structural and logical analysis of projects; scientific novelty of the article is associated with the development of methods for the synthesis and analysis of the effectiveness of innovative project ideas in the conditions of the formation of the ETO.

Keywords: Idea, Efficiency; System Approach; Technological Order; Analysis; Subject; Project; Factors, Modeling; Criterion

\section{INTRODUCTION}

The relevance of the research is determined by the importance of the synthesis of ideas for the implementation of innovative projects during the development of the eighth technological order (ETO). Additional relevance to this work can be given by the fact that there is a development of clip thinking in people belonging to generation $\mathrm{Z}$ (post-millennials). With this type of thinking, the logical thinking of an individual is difficult. Therefore, additional methodological developments are needed to help people with clip thinking synthesize innovative projects.

The hypothesis of this study is the assumption that: the study and analysis of methods for the synthesis of ideas and the formation of innovative projects during the development of the ETO will contribute to improving the efficiency of innovative activities of organizations and individuals during this period.

The aim of the work is to increase the efficiency of the process of synthesis of innovative ideas during the transition to the ETO

To achieve this goal, the following tasks are solved:

- research and clarification of the concept, functions and roles of an 
Synthesis of Effective Ideas of Innovative Projects During the Development of the Eighth Technological Order

- analysis of factors and methods of synthesis of innovative ideas in the process of development of a new technological order;

- formation of a methodology for the analysis of innovative ideas;

- description of the processes of modeling and business planning of projects for the implementation of these ideas.

The object of the article is innovative activity in the period of the ETO.

The subject of the article is the method of synthesis of effective innovative ideas during the formation of the ETO.

The analysis of scientific publications on the topic of this article shows the following. Researchers note that big ideas are a necessary element of a successful business [Straus (2005), p.2; Bandurina (2012), p.7-10]. The definition of the concept of "innovative idea" is considered as an important element of the theory of innovation activity [Maslyukovskaya (2013), pp.59-61]. In the course of innovation, much attention is paid to the process of generation and selection of innovative ideas [Lukina et al. (2019), p.54; Starodubova (2019), p.263-267; Sheve et al. (2021) , p.169-172; Hikmatov and Burieva (2020), p.19-21]. Specialized management systems are being created to manage ideas [Litvinova (2020), pp.165-168]. To generate innovative ideas, a theory of inventive problem solving was developed [Altshuller (1986), p.2]. An innovative idea affects the marketing system and the development of a system product [Kotler (1990), p.2; Sychev (2018), p.17-22]. Methods of generating innovative ideas are closely related: conducting preinvestment research [Kurilova (2017), pp.99-103]; the task of modernizing innovation activity [Glushchenko and Glushchenko (2015), pp.2]; theory of technological orders [Glushchenko (2021), pp.65-82]. In 2021, new directions for the synthesis of innovative ideas may be: convergent (nature-like) technologies [Kovalchuk (2021) ]; the process of ecosystem development [Borovik and Doroshenko (2020), pp.23-24].

To implement innovative ideas, it is necessary to create project teams [Glushchenko (2020), pp.272-287]. The introduction of innovative ideas into economic practice takes the form of innovative projects and affects the business model of the organization [Glushchenko (2020), pp.15-33]. When forming and implementing innovative ideas in practice, it is recommended to take into account that the post-millennial generation is characterized by "clip thinking". This complicates the logical thinking of the subjects of innovation [Howe and Strauss (2008), pp.109-111].

In general, the analysis of publications on the topic of the article allows us to talk about the relevance of the topic of this article.

\section{METHOD}

Innovation can be understood as innovation in the field of creating goods and services, objects of technology, technology, labor organization or management, using the advanced achievements of world science and best practices (experience) [Glushchenko and Glushchenko (2015), pp.59-61]. At the same time, the starting point and basis of any innovative project is the synthesis of the most innovative idea. This idea becomes the basis of the project.

The dictionary of Ozhegov S.I. asserts that an idea is: a reflection and generalization of human experience; a complex concept; a representation. The term "idea" can mean: the main, basic idea; the idea that determines the content of 
something (in this case, an innovative project), the mental image of this project; the concept of something (project); thought; intention; plan.

The Big Encyclopedia of Oil and Gas defines the concept of "innovative idea" in this way. An innovative idea is a real opportunity: the production of an original product, product or service; the creation of improved modifications or variants of these products; the creation of new product brands. An analysis of this definition shows that in this definition the emphasis is on the existence of the possibility of implementing the idea, and not on the innovative idea itself?

Other authors mean by an innovative idea an idea that is distinguished by novelty. This idea: is characterized by a certain target orientation; has potential social and/or economic utility (value). Is this definition of an idea immaterial in nature, and therefore can be recognized as more correct?

An innovative idea can be understood as combining three elements into a single whole: the main idea of an innovative project; the essence of the idea of an innovative product; a mental image of a business plan for the implementation of a specific project.

These three aspects of an innovative idea determine the content and order: the development of an innovative product (object of innovation); a strategic plan for the implementation of this entire innovative project.

It can be concluded that an innovative idea is characterized by the following properties: immaterial nature; connection with the mentality and thought process of a person; compliance with general and professional culture; potential usefulness to society and / or the economy; the ability to be the basis for the development of new products; the ability to be the basis for planning the implementation of innovative projects and much more.

Innovatively active subjects (subjects) can be: scientists; inventors; businessmen; engineers and others.

The sphere of activity of the subject of innovation affects the nature and content of the innovative ideas put forward by him.

It is believed that it is important for an innovatively active subject (businessman, engineer) to identify for himself certain sources of information that will allow him to synthesize a certain innovative idea. Such sources of information for the synthesis of innovative ideas can be certain types of knowledge: about the needs of consumers; about the market; about the development of new technologies, methods of production of materials; about existing geographical or structural gaps in systems to meet the needs of the population.

It can be recommended to study an innovative idea from the following points of view: the economic efficiency of the idea; feasibility at a given level of development of science and technology; the usefulness of the idea for customers or the possibility of meeting customer needs; the place of the satisfied (or created) need in the system of customer needs and values; assessment of the level of satisfaction of this type of customer needs at the time of product release; what are the time and quantitative characteristics of customer needs in this area; the need for additional development of the service sector and much more.

The key characteristics of an innovative idea can be called: the ability to assess the potential usefulness of an idea for society and/or the economy; compliance of this idea with trends in the development of science and practice; the use of advanced scientific achievements; the possibility of its implementation at the current level of development of science and technology; compliance of this idea with key state institutions (systems of relations) and others. 
There are cases when innovative ideas are put forward that are not rational (expedient, acceptable), productive ideas. Therefore, after the stage of putting forward ideas, for example, within the framework of collective generation of ideas, it is possible to analyze whether the idea is rational (expedient). Such an analysis can be performed in Table 1 .

Table 1 Analysis of the feasibility of an innovative idea

$\begin{array}{cccc}\text { № } & \begin{array}{c}\text { Numbers of analyzed innovative ideas/Factors } \\ \text { I } \Pi \text { (п) assessing the feasibility of an innovative }\end{array} & \begin{array}{c}\text { Evaluation of } \\ \text { idea No. } 1\end{array} & \begin{array}{c}\text { Evaluation of } \\ \text { idea No. } 2\end{array}\end{array}$

(3)

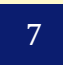

\begin{tabular}{|c|c|c|c|}
\hline 1. & $\begin{array}{l}\text { Compliance of the idea with the modern level of } \\
\text { development of science and technology }\end{array}$ & 7 & 8 \\
\hline 2. & $\begin{array}{l}\text { Compliance of the idea with the trends in the } \\
\text { development of science and technology }\end{array}$ & 6 & 5 \\
\hline 3. & $\begin{array}{l}\text { Compliance of the idea with organizational culture } \\
\text { and business norms }\end{array}$ & 5 & 7 \\
\hline 4 & $\begin{array}{c}\text { The influence of the idea on public culture and } \\
\text { morality }\end{array}$ & 7 & 6 \\
\hline 5. & Compliance of the idea with the norms of law & 8 & 9 \\
\hline 6. & Total: & 33 & 35 \\
\hline
\end{tabular}

System engineering can be recognized as a common method of forming innovative ideas and projects. Such system engineering is a field of knowledge, the system integration of which ensures the formation and successful implementation of innovative projects.

Within the framework of system engineering, innovative ideas perform the following functions: 1) act as a mental image in the processes of modeling and designing an innovative product; 2) be the mental basis for the formation of a business plan for the implementation of an innovative project; 3) act as the starting point for the formation of a paradigm for the implementation of a specific innovative project; 4) be the basis for the formation of requirements for the team of an innovative project; 5 ) be the basis for the formation of criteria for the effectiveness of the project and more.

The roles of an innovative idea can be called: ensuring the effectiveness of the process of implementing an innovative project; minimizing the risks of an innovative project.

An effective innovative idea is proposed to be understood as an idea that ensures the achievement of the goals of an innovative project: for a certain period of time; under the condition that the cost of resources does not exceed the allocated amount of resources.

At the same time, the task of finding the optimal innovative idea can be formulated. The optimal innovative idea can be considered an idea that ensures the achievement of the goals of the innovation project in the best way in accordance with the accepted criterion of optimality. To determine the level of optimality of an innovative idea, the following procedure can be proposed, which is reflected in Table No. 1. In the process of such analysis and selection of optimal ideas, each of these ideas can be evaluated, for example, on a 10-point scale. The results obtained for all evaluation factors can be summed up. 
Table 2 Assessment of the optimality level of an innovative idea

\begin{tabular}{|c|c|c|c|}
\hline $\begin{array}{c}\text { № } \\
\text { П/ா }\end{array}$ & $\begin{array}{l}\text { Numbers of analyzed innovative } \\
\text { ideas/Factors for evaluating the } \\
\text { effectiveness of an innovative idea }\end{array}$ & $\begin{array}{l}\text { Evaluation of } \\
\text { idea No. } 1\end{array}$ & $\begin{array}{l}\text { Evaluation of } \\
\text { idea No. } 2\end{array}$ \\
\hline (1) & (2) & (3) & (4) \\
\hline 1. & $\begin{array}{l}\text { Feasibility of the idea at this level of } \\
\text { development of science and technology }\end{array}$ & 3 & 5 \\
\hline 2. & economic efficiency of the idea & 5 & 4 \\
\hline 3. & $\begin{array}{l}\text { Assessment of the degree of satisfaction of } \\
\text { individual needs }\end{array}$ & 4 & 6 \\
\hline 4. & $\begin{array}{l}\text { Assessment of the degree of satisfaction of } \\
\text { public needs }\end{array}$ & 5 & 5 \\
\hline 5. & Resource requirements & 4 & 4 \\
\hline 6. & $\begin{array}{c}\text { The period of maintaining the competitiveness } \\
\text { of the project }\end{array}$ & 7 & 5 \\
\hline 7. & Impact on markets & 3 & 6 \\
\hline 8. & Итого: & 31 & 35 \\
\hline
\end{tabular}

Source: developed by the author

As a result of the comparative analysis of two innovative ideas performed in Table 2, idea No. 2 can be recognized as the best (optimal).

It should be borne in mind that additional relevance to the topic of this article is given by the fact that there is currently a global systemic crisis. This crisis is connected with the inconsistency of institutions with new technologies of the ETO. Therefore, the process of forming a new technological order affects the economy, society, institutions, public and individual consciousness [Glushchenko (2021), pp. 22-39].

At the same time, the process of forming a new technological order is the very process of overcoming the global crisis of the crisis.

It can be predicted that in the field of science, education and innovation, the new technological order will be characterized by the following features: science, innovation and education are recognized as key resources for the development of society; the process of decentralization in science and management of this sphere will continue; the center of gravity will move to small laboratories; the division into fundamental and applied science will become more and more conditional (now this trend is most clearly manifested in the development of natural-like technologies and ecosystems); the main organizational form of science and education will be projects (project approach).

From a substantive point of view, the development of science and technology in the period of the ETO will be associated with: firstly, an ever deeper penetration into the nature of the material world (nanotechnology, environmentally friendly technologies and resource-saving technologies); a more comprehensive and indepth knowledge of the properties of the human brain and psyche (neurotechnology, information technology, digital technology), and others.

The ETO will be characterized by the development of such types of new technologies: information technologies; intelligent technologies; neurotechnologies; digitalization technologies; nanotechnologies; resource-saving technologies, environmentally friendly technologies. At the same time, these 
technologies can be used to change people's ways of thinking [Glushchenko (2021), pp. 17-40]. The application of these technologies to existing technologies and objects of previous technological orders should become the main direction of the development of innovative ideas for the period up to 2040.

The synthesis of the idea of an innovative project can be: firstly, random, heuristic in nature; secondly, the result of a purposeful search for such an idea (conceptual in nature).

As methods of purposeful search for innovative ideas for the implementation of business projects, the following methods can be named: analogies, which may result from a system of mentoring and/ or the use of "recipes"; the use of a "morphological box" [Glushchenko and Glushchenko (2000), pp. 214]; the operator of the RVS "size-time-cost"; brainstorming; collective generation of ideas; The Theory of Solving Inventive Tasks [Altshuller (1986), p.2]; the use of conceptual approaches and developments, etc.

A conceptual approach can mean the following:

- the idea of the project should either follow from some concept (for example, the theory of technological orders, the theory of solving inventive tasks, etc.);

- the formation of the project should take place on a certain conceptual basis (philosophical concept);

- the idea of an innovative project should be organically integrated into the concept of development of this area of science and technology.

The concept of an innovative project will be called the most general systematic view of a new innovative project. Within the framework of the eighth technological mode, such a conceptual approach can be expressed in an effort to maximize the use of new technologies of this mode to increase the comfort and safety of customers' activities.

An example of a conceptual approach to the synthesis of innovative ideas of projects aimed at the development of the ETO in such an economic sector as shipbuilding is given in Table 3.

Table 3 Table of innovative ideas in the modernization of the ship project during the transition to the ETO (fragment)

\begin{tabular}{|c|c|c|c|c|}
\hline $\begin{array}{c}\text { № } \\
\text { П/ா }\end{array}$ & $\begin{array}{c}\text { Technologies } \\
\text { of the eighth } \\
\text { way } \\
\text { / Names of } \\
\text { subsystems of } \\
\text { the vessel }\end{array}$ & nanotechnology & Neurotechnology & $\begin{array}{l}\text { Digitalization } \\
\text { technologies }\end{array}$ \\
\hline 1. & $\begin{array}{l}\text { Hull of the } \\
\text { vessel }\end{array}$ & $\begin{array}{l}\text { Increasing the } \\
\text { strength of the hull } \\
\text { parts, increasing the } \\
\text { wear resistance of the } \\
\text { paint }\end{array}$ & $\begin{array}{l}\text { Registration of } \\
\text { reactions of the ship's } \\
\text { crew and designation } \\
\text { of the most dangerous } \\
\text { parts of the hull }\end{array}$ & $\begin{array}{l}\text { Recording of hull } \\
\text { vibrations, noise, } \\
\text { optimization of } \\
\text { working and rest } \\
\text { modes of the ship's } \\
\text { crew, taking into } \\
\text { account loads }\end{array}$ \\
\hline 2. & Ship's engine & $\begin{array}{l}\text { The increase in } \\
\text { strength and wear } \\
\text { resistance of the ship's } \\
\text { engine parts, the } \\
\text { increase in the quality } \\
\text { of its anti-corrosion } \\
\text { coating }\end{array}$ & $\begin{array}{l}\text { Registration of } \\
\text { psychophysical } \\
\text { reactions of the } \\
\text { captain and others to } \\
\text { vibration and noise } \\
\text { modes during } \\
\text { operation }\end{array}$ & $\begin{array}{c}\text { Fixation and } \\
\text { recording of } \\
\text { operating modes, } \\
\text { vibrations and noise } \\
\text { of the ship's engine, } \\
\text { optimization of the } \\
\text { captain's working } \\
\text { and rest modes }\end{array}$ \\
\hline
\end{tabular}




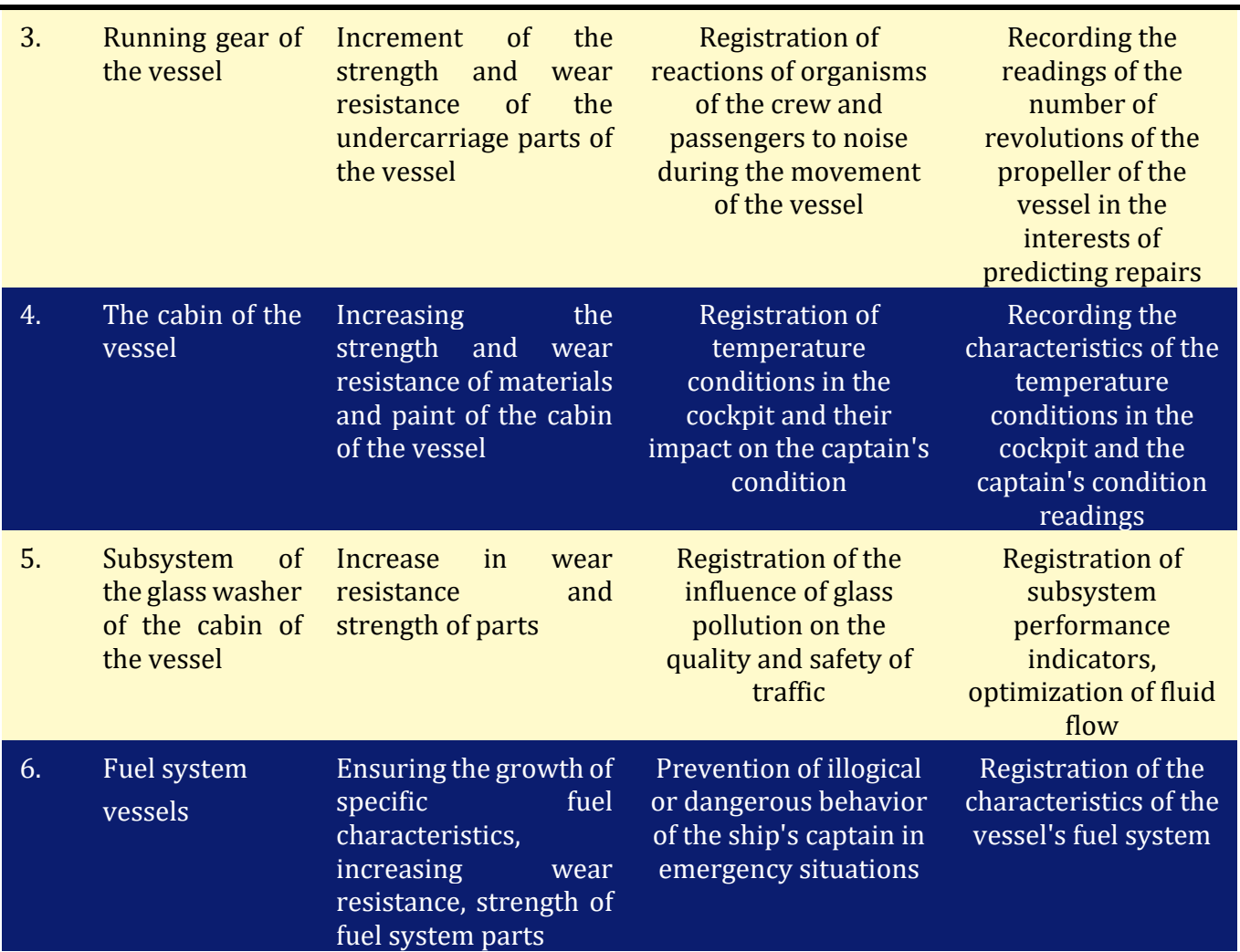

Source: developed by the author

Within the framework of the conceptual approach to the synthesis of ideas of innovative projects based on the application of technologies of the ETO, such as neurotechnology, nanotechnology and others to existing technologies and objects of previous technological orders, can become the main direction of the development of innovative ideas for the period up to 2040.

In fact, each quadrant of Table 3 can become a source of innovative ideas. Let's explain this idea with an example.

Example 1. Consider the quadrant of Table No. 3, located at the intersection of the sixth row and the third column (6:3). In this quadrant it is written: "Registration of the characteristics of the fuel system of the vessel." This allows you to timely warn the ship's captain about the dangerously low fuel level in the tank. The study of the possibility of using new technologies of the ETO in ship design modernization projects has shown the possibility of using information technologies to create voice assistants for the ship's captain. In particular, such an assistant can issue a voice signal in the event that the level of liquid in the tank (fuel or other process fluids, for example, cabin glass washer fluid) becomes below the level that is defined as critical (lowering the level is unacceptable). The introduction of such voice assistants will increase the safety of river and sea vessels and their operational readiness coefficient, and eliminate sudden deterioration of operating conditions.

The more times a new technology (voice assistant) is introduced into new and already known objects, the higher the rate of its multiplication with objects of previous technological orders.

The higher the level of animation of a new technology, the more times it has been put into practice and the higher the level of its economic efficiency.

At the same time, the process of implementing an innovative project itself should be based on a certain paradigm, the concept of innovation activity, which 
includes as its elements: philosophy, ideology, culture, politics, strategy and tactics of project implementation [Glushchenko (2021), pp. 17-40].

At the same time, the very idea of an innovative project becomes an element of the ideology of an innovative project. An innovative idea becomes an element of that part of the ideology that defines the main goal of the project. As you know, the second component of the project ideology ensures the distribution of power in innovative projects (leader, team, external stakeholders).

A well-known scientist, the expert believes that during the period of technological change, the most common object of innovation is the development of new technologies, and not individual products (goods and services). They also propose the concept of generating nature-like technologies [Kovalchuk (2021) ]. Ecosystems and the ecosystem approach in the implementation of business projects can be considered as a particular direction of nature-like technologies [Borovik and Doroshenko (2020), pp. 23-24].

Compared to the marketing approach, the ecosystem approach is characterized by a number of methodological features. These are the following features: orientation not to the needs, but to the lifestyle of the client; strategic approach to project implementation; creation of complex products (goods and services) for its target audience; the desire to avoid competition by creating pioneering (unparalleled) products; minimizing damage and compensation for environmental damage, etc.

In 2021, in Russia, a number of large organizations from various sectors of the economy (banks, information companies, etc.) are creating and advertising their ecosystems in the media.

The subject of the formation of the concept of an innovative project is the project team (project group). The theoretical foundations of the creation and work of project teams are reflected in work [Glushchenko (2020), pp. 272-287].

In this article, we will proceed from the assumption that the project team, in the process of forming the project idea, acts: scientifically justified; independently; in its own interests; strives to achieve maximum results (reducing the payback period, increasing the net reduced effect, the return on investment index, etc.).

Often, in the process of implementing an innovative business idea, its creative modernization is required to meet the actual situation. The creativity of the project team plays an important role in this process. The creativity of the project team can be understood as the willingness of this team to synthesize fundamentally new and/or modernized project ideas. The creativity of the project team can be characterized by the totality of its qualities: receptivity to the problems of the project; understanding of the existing shortage of solutions; the ability to generate ideas for solutions; the ability to propose and test hypotheses about the qualities and characteristics of the project; predictive and actual description of the result of the innovation project, and others.

To improve the quality of the ideas of innovative projects, an algorithmic approach can be applied to solving the problem of synthesis of this idea. The algorithm for the synthesis of an innovative idea is an unambiguous sequence of operations aimed at the synthesis and justification of an innovative idea.

The algorithm for synthesizing an innovative business idea includes: detecting a business problem in an organization; analyzing business and the situation; generating solutions to the problem; forming an efficiency criterion; evaluating the feasibility and effectiveness of the project; making a management decision on the development of a specific project; forming a project team; developing a project as a set of documentation defining the appearance of an innovative project; forming an 
innovative project implementation plan; project implementation; monitoring project effectiveness.

At the same time, the process of implementing an innovative project itself should be based on a certain paradigm of innovation activity, which includes as its elements: philosophy, ideology, culture, politics, strategy and tactics of project implementation [Glushchenko (2021), pp. 17-40].

At the same time, the idea of the project itself becomes part of its ideology, namely the part of it (ideology) that determines the main goal of the project. As you know, the second component of the project ideology ensures the distribution of power in innovation processes (leader, team, external stakeholders).

A well-known scientist, an expert believes that during the period of technological change, the most common object of innovation is the development of new technologies, and not individual products (goods and services) [Kovalchuk (2021) ].

In this article, we will proceed from the assumption that the project team, in the process of forming the project idea, acts: scientifically justified; independently; in its own interests; strives to achieve maximum results (reducing the payback period, increasing the net reduced effect, the return on investment index, etc.).

To improve the quality of innovative ideas, an agorhythmized approach to the synthesis of this idea can be used. An algorithm is an unambiguous sequence of operations aimed at achieving a specific goal (making a profit from innovation). The factors of formation of the algorithm for the synthesis of innovative business ideas cover the following components:

1) the mentality of an innovatively active subject;

2) composition and organizational culture of the project team;

3) technological order of the field of activity;

4) the level of the "technological pyramid";

5) type of market (producer, consumer);

6) type of innovation (industrial, post-industrial);

7) type of product: product or service;

8) the nature of the problem being solved (functional, structural, parametric);

9) the object of innovative activity (goods, services, technology, transformation of human consciousness and others.

Let's consider these factors of the formation of an innovative idea in more detail.

The mentality of an innovatively active subject is the most important factor in the synthesis of an innovative idea. At the same time, the mentality is considered in several of its elements as: the psychological basis of an innovative project; the mental basis for the synthesis of the idea of a new project; a factor in the formation of a project team; the basis of the creative process in the team of a specific project.

The analysis shows that dictionaries do not give an unambiguous definition of the concept of "mentality".

Most often, the word "mentality (from Latin ... mens - mind, soul, spirit, mind)" refers to the mindset, worldview, complex of mental, emotional, cultural characteristics, value attitudes and orientations inherent in the subject of social or economic activity.

We will call the "innovative mentality": the perception of the world, the level of abstraction of thinking, the mindset, the scale of values of an innovative active individual or project team. The innovative mentality creates the internal motivation 
of the subject of innovation to engage in innovative activities as a source of obtaining funds necessary to meet the needs of a person (or team).

We will proceed from the fact that the development of innovations in the field of, for example, nanotechnology requires a mentality that is associated with the ability of human psychology to sense the hidden structure of material objects. At the same time, research in the field of neurotechnology requires a mentality capable of exploring deep processes in the human brain and psyche.

The composition and organizational culture of the project group (team) have an impact on several characteristics of the innovation process at once: the probability of synthesis of an innovative effective business idea; ways to identify and overcome the problems of an innovative project; the moral and psychological atmosphere in the project group (team). At the same time, the moral and psychological atmosphere can contribute to the generation of innovative ideas by group members or suppress their creativity and other things.

Practice shows that there is reason to say that mentality plays an important role in the process of forming a project team. The leader of the project group forms his innovative team based on the subconscious analysis of the mental characteristics of the team members. The leader chooses people who are mentally close to him in his innovative team. This technique when choosing a project team can be called "multiplication in the mind." Mental multiplication creates synergy in the activities of the project team. This is because multiplication provides the conditions for: joint generation of ideas by team members; effective exchange of implicit knowledge; coordination of actions of team members in the process of work; minimizing conflicts within the project team; creating a favorable moral climate in the team and much more.

The technological order of the field of activity determines the intellectual level, methods and organization of innovative activity. For example, innovations in the field of engine building belong to the fifth technological order (electric motor) [Glushchenko (2021), pp. 17-40]. The objects of such innovative activity are the development and production of electric motors and internal combustion engines. For such innovative activities, there are research institutes (research institutes) for the design of engines. At the same time, the innovation process itself is distributed: engine development (responsible for the development of research institutes); engine manufacturing plants are responsible for the production of engines; transport companies are responsible for the operation of the engine.

And the activities of modern Internet companies belong to the ETO (neuro- and nanotechnology). The object of their activities are: information exchange; information search; thinking process; optimization of information perception and emotional sphere of people. The form of organization of innovation activity is project teams. At the same time, one team - a project team (a group of people) ensures that all work is carried out throughout the life cycle of their innovative ideas and information products created on their basis.

From the point of view of mentality, the following is also important. The level of abstractness of thinking of developers of electric motors (the fifth technological way) is lower than the level of abstractness of thinking of developers of nanotechnology (the ETO). This is because the engine is tangible. The engine can be seen, touched with your hands. And the nanotechnology process is not tangible. This forces the brain to operate with more abstract categories than weight, size, etc.

It is possible to formulate such an axiom: the level of abstractness of thinking for working with technologies of the subsequent technological order is always higher than the level of abstractness of thinking that is necessary for working in the 
previous technological order. Let's call this axiom: "the axiom of increasing the level of abstractness of thinking" in the process of technological progress.

At the same time, mental differences can lead to mental conflicts between members of the project team [Glushchenko (2021), pp. 22-39].

The level of the "technological pyramid" also affects: the orientation (object) of an innovative idea; the probability of synthesis of a productive innovative idea. Considering this issue, it should be remembered that each technological order is a five-level technological pyramid. At the first (highest) level of this pyramid are conceptual developments (concepts, ideas, philosophy). At this level, the object of innovative ideas are conceptual developments, for example, the scientific theory of technological orders [Glushchenko (2021), pp. 65-82].

At the second level are the developers of new technologies (based on the results of concepts). At this level, the objects of innovative ideas during the ETO will be: nanotechnologies for various purposes; various forks of neurotechnologies and more.

At the third level of the technological pyramid are the developers of the means of production. The objects of innovative ideas at this level of the technological pyramid will be: 3D printers; voice assistants and more.

At the fourth level of the technological pyramid of the ETO are operating and servicing organizations. They (organizations) operate and maintain the means of production of the ETO. The objects of innovative ideas at this level of the technological pyramid can be: new schemes for the operation of means of production; new schemes for the technical service of means of production and more.

Raw material organizations are located on the fifth level. For the activities of these organizations within the framework of the ETO, the objects of innovative ideas can be: the creation of ecosystems; the creation of nature-like (convergent) technologies; the development of resource-saving technologies; the creation of environmentally friendly technologies.

The specifics of the activity at each of these levels of the technological pyramid (within the framework of one technological order) determines the features of the synthesized innovative ideas and methods of their implementation.

At the same time, innovative ideas at the upper levels of the technological pyramid are usually more abstract than innovative ideas at the lower levels of the technological pyramid.

The type of market (producer, consumer) also affects the nature of the synthesized ideas of innovative projects. In the manufacturer's market, innovative ideas are aimed at increasing the volume of production of existing products. In the consumer market, innovative ideas are aimed at such objects of innovation: 1) more complete satisfaction of customer needs; 2) victory in the competition for your consumer.

The type of innovation (industrial, post-industrial) can also influence the object and subject of an innovative idea, project. In the industrial approach, the object of innovative ideas is a more complete satisfaction of the known needs of customers (buyers). With a post-industrial approach, innovative ideas are aimed at creating new ones: ways to meet existing needs; synthesis of new tools to meet needs; ideas for a new use of well-known goods, etc. In the post-industrial campaign, the subject of innovative ideas is the effective use of the achievements of science and technology. Therefore, innovative ideas of a post-industrial nature are based on: firstly, the creation of new needs; satisfaction of these needs through the maximum use of the latest achievements of science and technology. 
The type of product of innovative ideas (product or service) is a factor that affects innovative ideas and the possibility of their practical implementation. This is determined by the fact that the product is material. For this reason, the design of the product and the production process of this product are more related to material factors (technologies, raw materials, tools, machines, etc.). The service has an immaterial character. The service is more focused on meeting the individual needs of a particular client. At the same time, services: have the properties of: immateriality; non-preservation; They are characterized by inconstancy of quality; often services are provided in the presence of the client and other things [Glushchenko and Glushchenko (2015), c.11].

The nature of the problem solved by innovation has its influence on the synthesis and practical implementation of an innovative idea. Such innovative ideas can be put forward: the idea of changing the functions of the innovation object, the idea of changing the structure of the product, the idea of changing the parameters of the product. This division of innovative ideas affects the scale of the project. Therefore, which (functional, structural, parametric) innovative idea will be the basis of an innovative project will determine the method and resource intensity of solving the problem.

In addition, by the nature of the problem in the organization, there are two types of problems: the organization does not achieve its goals; the organization does not use its existing capabilities. Based on this, ideas can be synthesized aimed at: removing obstacles that prevent the achievement of the goals of the organization; ideas aimed at using market opportunities.

Modeling is used in the synthesis and analysis of the effectiveness of innovative ideas and projects. The conditions for the effectiveness of the process of modeling innovative ideas can be called:

1) modeling should be sufficiently detailed in order to ensure the similarity and adequacy of the model with the object of modeling- the original: technology, object or product. The fulfillment of this condition leads to an increase in the costs of creating a model and the modeling process itself;

2) the model should be simple enough so that the costs of analyzing innovative ideas using models are significantly lower than the costs of the same research using a real object.

Modeling is used to increase efficiency and reduce the risks of implementing innovative ideas. The modeling language is the following forms of expressing information about the modeling object [Glushchenko and Glushchenko (2000), c.155; Workbook on forecasting (1982)]:

1) verbal description is considered as a simple and informal representation of information about the modeling object (innovative idea);

2) graphical representation in the form of a graph tree of project goals, graphs of changes in characteristics, drawings, histograms, nomograms;

3) decision matrices, flowcharts that allow you to display the structure and/or logical connections of the elements of the modeling object;

4) description of the modeling object in the form of a system of equations, formulas using variable characteristics of this object and more.

Each of the known types of models uses its own types of displaying information about an innovative project (modeling object).

The principles of forming models of innovative projects can be called the following provisions [Glushchenko and Glushchenko (2000), p.182; Workbook on forecasting (1982)]: 1. the principle of compromise between the expected accuracy of modeling results and the complexity of the model; 2 . balance of accuracy 
(proportionality of systematic and random error of modeling); 3 . a variety of model elements, which should be sufficient to study multifunctional and multivariate objects; 4 . visibility of the model for the researcher and the customer; 5 . block description of the model; 6 . certain specialization of models.

When a model is created, the following requirements are imposed on it [Glushchenko and Glushchenko (2000), p.182; Workbook on forecasting (1982)]: completeness, adaptability, the model should provide the possibility of making significant changes; the model should be sufficiently abstract; it should meet the requirements limiting the time of solving the problem; the model should provide for its implementation using existing technical means; the model should provide an increase in useful information about an innovative project (modeling object); the model should be built using generally accepted terminology; the model must provide for verification of its truth (compliance with its original); the model must have the property of stability with respect to errors in the source data (robustness).

The use of models during the synthesis and analysis of innovative ideas makes it possible to increase the effectiveness of solutions related to the implementation of the project. In this case, an innovative project is considered as a set of coordinated actions. In this case, using models, the following tasks can be consistently solved: search forecasting - normative forecasting - strategic planning - business planning long-term planning - current planning - operational planning- operational planning.

In the world practice of business process modeling, the following types of business models are most often used: the model of Alex Osterwalder; the business model of M. Johnson, K. Christensen, H. Kagermann.

The business model of M. Johnson, K. Christensen, H. Kagermann includes four blocks. The first three blocks describe the internal environment of the project (organization). The first block reflects the following elements of the project: technologies; personnel; equipment; products; information; supply channels; alliances, partners. The second block of this model describes the following elements of the project: processes; rules; norms. The third block of this model describes the model of generating income for the project: the cost structure; the model of marginal profit; the speed of circulation of resources. The fourth block of this model is external and resultant. This block of the model describes the value offered to consumers. This block of the model covers the following characteristics: a need that needs to be satisfied; the main consumers; the company's offer to its customers.

This model allows you to take into account factors that affect the effectiveness of the organization's business processes. However, such a model does not allow taking into account the logical connections between the elements of the business process. This can make it difficult to analyze the impact of various factors on the financial results of an innovative project, the activities of an organization.

A business model that takes into account the relationships in the structure of the business process was proposed by Alex Osterwalder and Yves Pinier in their famous book "Building business Models". A. Osterwalder expressed the point of view that a business model is a tool. Such a tool is needed to describe the basic principles of forming and ensuring the successful operation of the organization. The main point of their proposal is to create a business model. This business model should meet the following requirements: it would be well structured; it would be understandable to everyone; it would be placed on a single A4 sheet. For these purposes , A. Osterwalder created a business model of the project in the form of a map. This model includes nine blocks. The block structure of this model allows analyzing each of the blocks separately. At the same time, this model provides the possibility of a systematic analysis of the innovative business process. Such a system 
analysis allows you to study the impact of changes in one of the elements on all other elements and on the entire business process as a whole.

Let 's describe the blocks of model A. Osterwalder. In this model, we will highlight such parts of model A. Osterwalder: revenue (right) part of the model; expenditure (left) part of the model. At the same time, the revenue part of the model includes the following blocks: 1. block "Value proposition"; 2. block "Customer segments" (customersegments); 3. block "Customer relationships" (customer relationships); 4. Block "Channels" (channels) of customer relationships; 5. "Revenue streams" (revenue streams).

The expenditure part of this model consists of the following blocks: 6 . block "Key resources"; 7. block of characteristics "Key activities" (key activities)- the main business processes; 8. block "Key partners" (key partners) for business; 9. "Cost structure" of business. This model allows you to analyze the business process taking into account the structure and characteristics of the business process.

An even more structured model of the innovation project was proposed by V.V. Glushchenko and I.I. Glushchenko in work [Glushchenko and Glushchenko (2015), pp.110-115]. In this model, it is proposed to estimate the probability of successful implementation of an innovative project based on the probabilities of successful solution of project problems. At the same time, the whole set of project problems is divided into two parts: external problems of the project; internal problems of the innovation project.

In the study of the internal problems of the project, the well-known three-level product model of Phillip Kotler was used. In this model, F. Kotler identified the following levels of the product: the 1st level characterizes its main purpose; the 2nd level of the model describes the product in real execution (specific properties of the product); the 3rd level represents "goods with reinforcement" (credit, warranty, after-sales service, etc.) [Kotler (1990), pp. 265]. In order to reflect the strategic and environmental impact of the product, it was proposed to supplement this model with the fourth level (environmental and strategic) [Glushchenko and Glushchenko (2015), pp.110-115]. In this model, the entire process of implementing an innovative project is divided into two groups of management decisions: solutions to overcome external problems of the project; solutions to internal problems of the project. The content of these design solutions, respectively, was described in two tables (see Tables No. 2 and 3) [Glushchenko and Glushchenko (2015), pp.110-115].

Table 4, Table 5 shows an abbreviated version of these tables.

Table 4 Description of external factors influencing the successful implementation of an innovative project (fragment)

\begin{tabular}{|c|c|c|c|c|c|}
\hline \multirow{3}{*}{ № } & & \multicolumn{4}{|c|}{ External success factors of an innovative project } \\
\hline & $\begin{array}{l}\text { Source of the } \\
\text { external }\end{array}$ & $\begin{array}{l}\text { Name of } \\
\text { the external }\end{array}$ & $\begin{array}{l}\text { The content of the } \\
\text { external }\end{array}$ & $\begin{array}{l}\text { Probability } \\
\text { of successful }\end{array}$ & $\begin{array}{l}\text { The } \\
\text { probability of }\end{array}$ \\
\hline & $\begin{array}{l}\text { factor of the } \\
\text { project }\end{array}$ & $\begin{array}{l}\text { factor of the } \\
\text { project }\end{array}$ & $\begin{array}{l}\text { factor of the } \\
\text { innovation project }\end{array}$ & $\begin{array}{l}\text { solution of } \\
\text { the project } \\
\text { problem }\end{array}$ & $\begin{array}{l}\text { an } \\
\text { unsuccessful } \\
\text { solution to the } \\
\text { project } \\
\text { problem }\end{array}$ \\
\hline (1) & (2) & (3) & (4) & (5) & (6) \\
\hline 1. & $\begin{array}{c}\text { global } \\
\text { scientific and } \\
\text { technological } \\
\text { progress }\end{array}$ & $\begin{array}{c}\text { Competitiveness } \\
\text { of project } \\
\text { technologies }\end{array}$ & $\begin{array}{c}\text { Competitiveness of } \\
\text { technologies and } \\
\text { technical solutions } \\
\text { in an innovative } \\
\text { project }\end{array}$ & Ptc, & $(1-\mathrm{Ptc})$ \\
\hline
\end{tabular}




\begin{tabular}{|c|c|c|c|c|c|}
\hline 2. & $\begin{array}{l}\text { global goods } \\
\text { market }\end{array}$ & $\begin{array}{l}\text { Consumer } \\
\text { qualities of the } \\
\text { product }\end{array}$ & $\begin{array}{l}\text { Competitiveness of } \\
\text { consumer properties } \\
\text { of the product }\end{array}$ & Pct & $(1-\mathrm{Pct})$ \\
\hline 3. & $\begin{array}{l}\text { global } \\
\text { financial } \\
\text { market }\end{array}$ & $\begin{array}{c}\text { Ensuring } \\
\text { sufficient } \\
\text { financing of the } \\
\text { project }\end{array}$ & $\begin{array}{l}\text { The project must } \\
\text { have sufficient } \\
\text { sources of funding }\end{array}$ & Ppf & $(1-\mathrm{Ppf})$ \\
\hline 5. & $\begin{array}{l}\text { Global } \\
\text { Currency } \\
\text { Market }\end{array}$ & $\begin{array}{c}\text { Price } \\
\text { competitiveness } \\
\text { of the product }\end{array}$ & $\begin{array}{l}\text { The product must be } \\
\text { competitive in price, } \\
\text { taking into account } \\
\text { the exchange rate } \\
\text { and currency risk }\end{array}$ & Pcc & $(1-\mathrm{Pcc})$ \\
\hline 6. & $\begin{array}{l}\text { Geopolitics, } \\
\text { global } \\
\text { competition }\end{array}$ & $\begin{array}{l}\text { The geopolitical } \\
\text { risk of the } \\
\text { product }\end{array}$ & $\begin{array}{l}\text { The goods must be } \\
\text { protected from } \\
\text { manifestations of } \\
\text { geopolitical risk } \\
\text { (sanctions, } \\
\text { embargoes, payment } \\
\text { moratorium, etc.). }\end{array}$ & Pgr & (1-Pgr) \\
\hline
\end{tabular}

Source: developed by the author.

Table 5 Description of internal factors of successful implementation of the innovative idea of the project (fragment).

\begin{tabular}{|c|c|c|c|c|c|}
\hline \multirow[t]{2}{*}{ № } & \multicolumn{5}{|c|}{ Internal factors of the innovation project } \\
\hline & $\begin{array}{l}\text { Source of } \\
\text { the } \\
\text { internal } \\
\text { factor of } \\
\text { the } \\
\text { project }\end{array}$ & $\begin{array}{l}\text { Name of the } \\
\text { internal } \\
\text { factor of the } \\
\text { innovation } \\
\text { project }\end{array}$ & $\begin{array}{l}\text { The content of the } \\
\text { internal factor of the } \\
\text { innovation project }\end{array}$ & $\begin{array}{l}\text { The } \\
\text { probability of } \\
\text { a successful } \\
\text { solution to } \\
\text { the problem }\end{array}$ & $\begin{array}{l}\text { The probability } \\
\text { of an } \\
\text { unsuccessful } \\
\text { solution to the } \\
\text { problem }\end{array}$ \\
\hline (1) & $(2)$ & (3) & (4) & (5) & (6) \\
\hline 1. & $\begin{array}{l}\text { Product. } \\
\text { First level }\end{array}$ & $\begin{array}{l}\text { purpose of the } \\
\text { product }\end{array}$ & $\begin{array}{l}\text { correct determination } \\
\text { of the purpose, } \\
\text { appearance of the } \\
\text { product and the need } \\
\text { for it from customers }\end{array}$ & $\mathrm{P}_{\mathrm{pp}}$ & $\left(1-P_{p p}\right)$ \\
\hline 2. & $\begin{array}{l}\text { Product. } \\
\text { Second } \\
\text { level }\end{array}$ & $\begin{array}{c}\text { The main } \\
\text { characteristics of } \\
\text { the product }\end{array}$ & $\begin{array}{l}\text { Achieving product } \\
\text { characteristics that } \\
\text { ensure customer } \\
\text { satisfaction }\end{array}$ & $\mathrm{P}_{\mathrm{cp}}$ & $\left(1-P_{\mathrm{cp}}\right)$ \\
\hline 3. & $\begin{array}{c}\text { Product. } \\
\text { Third } \\
\text { level }\end{array}$ & $\begin{array}{l}\text { Measures that } \\
\text { strengthen the } \\
\text { position of the } \\
\text { product }\end{array}$ & $\begin{array}{l}\text { Formation of a set of } \\
\text { measures to stimulate } \\
\text { the purchase of goods } \\
\text { (credit, service, } \\
\text { warranty, brand, etc.) }\end{array}$ & $P_{m p}$ & $\left(1-P_{m p}\right)$ \\
\hline 4. & $\begin{array}{l}\text { Product. } \\
\text { Fourth } \\
\text { level }\end{array}$ & $\begin{array}{l}\text { Strategic impact } \\
\text { of the product on } \\
\text { the market, } \\
\text { ecology and } \\
\text { society }\end{array}$ & $\begin{array}{l}\text { The product should } \\
\text { not lead to market } \\
\text { destabilization, } \\
\text { environmental } \\
\text { damage, damage to } \\
\text { society in a strategic } \\
\text { perspective }\end{array}$ & $\mathrm{P}_{\mathrm{si}}$ & $\left(1-P_{s i}\right)$ \\
\hline
\end{tabular}

After carrying out such modeling, it is necessary to form a business plan for an innovative project. Such a business plan is based on the results of business process modeling. Therefore, after modeling business processes, it is possible to draw up a 
business plan for an innovative project. Such a business plan is a management decision of the organization's management on the implementation of a specific innovative project, innovative business development of this organization. In this article, the functions of business planning in the process of implementing innovative projects include:

1) research on the feasibility and effectiveness of the project;

2) description of the main characteristics of the project: product, customers, market capacity, sales volume, brand, marketing program, etc.;

3) development of the project's production system (site, technologies, equipment, raw materials, personnel, etc.);

4) justification of the sources and schedule of project financing;

5) assessment of professional requirements for project personnel;

6) study of project risks and development of measures to reduce such risks;

7) calculation of the projected financial indicators of the project.

The roles of the business plan of an innovative project in this work can be called: increasing the degree of readiness of the project team for its implementation; reducing risks during the implementation of the project.

According to the UNIDO methodology, the business plan should describe:

1) Generalized conditions for the implementation of an innovative project and its initial data, including a description of team members and research and projects implemented by team members.

2) Description of the market and characteristics of the capacity of the organization (enterprise). In this section of the business plan of the innovation project, they investigate: the type of market and demand, make a sales forecast, reflect the characteristics of the production program, including describing by-products and waste disposal costs, characterize the sufficiency and the possibility of an additional increase in the production program of the organization (enterprise).

3) Explore the material factors of production, including: basic materials, raw materials, auxiliary materials, fuel, energy resources, the situation with the supply at present and in the future, etc.

4) Characterize the location and area: factors and the results of the preliminary selection of a production site, the cost of land and the additional cost of bringing this area in a state suitable for use in this project.

5) Design documentation is provided, which covers a preliminary description of the framework of an innovative project, a description of the necessary technologies and equipment, options for placing this equipment on production areas, an assessment of investment costs for this equipment, the construction of necessary buildings and structures, a description of the construction materials used, and others.

6) Description of the organization of the enterprise and assessment of its overhead costs, including the following sections: sales, production, management administration; approximate organizational structure; estimated overhead costs: factory, financial, administrative.

7) Characteristics of the labor resources necessary for the implementation of the project: the projected need for personnel with a division into categories of personnel and an estimate of personnel costs (labor resources).

8) Description of the projected timing of the project. 
9) Projected financial and economic results, including information of the following kind: sources of project financing; project capital structure, total investment costs, estimated assets, working capital, payback period, simple profit margin, break-even point, internal profit margin and other characteristics.

10) Results of risk research in the implementation of an innovative project, methods of their reduction, risk insurance [Glushchenko and Glushchenko (2000), p. 251; Glushchenko (2006), p.160-210].

The financial characteristics of the project (payback period, net reduced effect, return on investment index, etc.) can be calculated taking into account the risks according to the formulas given in works [ Glushchenko (2006), p.160-210].

\section{DISCUSSION}

The results of this article allow us to conclude that conceptual works on the theory of technological orders can be an important source of innovative ideas that are aimed at the development of a new technological order. At the same time, the concept of technological development forms a methodological basis for the comprehensive modernization of industrial enterprises at the onset of the ETO [Glushchenko (2021), p. 65-82; Glushchenko (2021), p. 17-40]. An integrated approach to the modernization of enterprises is very important due to the fact that individual innovations may not be enough to maintain the competitiveness of an enterprise in a new technological order.

When developing business- plans for innovative projects, it is necessary to additionally take into account the features and existence of: the marketing strategy of the organization (enterprise); the duration of the product life cycle; the nature of the market cycle of products; the features of the financial cycle of the organization. At the same time, the normal market cycle of goods can be divided into the following stages: bringing the goods to the market; increasing sales; maturity of the goods (sales have a constant value); saturation of the market; decline (decrease in sales); withdrawal of goods from the market. Objectively, the existing amount of information about the object of the innovation project is determined by the stage of implementation of the innovation project, the stage of the product development cycle.

In the theory of designing goods of high-tech engineering, it is customary to distinguish such stages of the life cycle of such goods (products): the stage of development; the stage of production of the product (manufacture); execution (stage) of commissioning and adjustment (adjustment); the stage of circulation of the product on the market; the stage of operation of the product by its owner; the stage of disposal of the product or modification of high-tech goods.

At the same time, the stage of development of high-tech engineering products can act as an independent product development cycle. Such a cycle of development of high-tech products (goods) of mechanical engineering, in turn, is also divided into the following stages: an advance project or research work (R\&D); a draft design; a technical design of a product; a stage of prototypes of products.

In the process of completing the stages of development of an innovative product, the degree of uncertainty associated with an innovative project decreases, so the amount of information that the project team has about the project as an object of innovation and the project as a set of actions increases.

At the stage of an advance project or research work (R\&D), information of this kind becomes known: a set of operating conditions of the product; product functions; an enlarged model of the innovation object; key production technologies 
and more. In this regard, at this stage of development, the existence of such types of product representations is possible: intuitive (implicit knowledge of the project team), subject and functional decomposition representation of the innovative object.

Recall that the standard representation is usually called the minimum amount of information that is necessary in order to implement an innovative project. The description of typical representations of complex innovative objects is given in work [Glushchenko and Glushchenko (2000), pp.126-133].

At the subsequent stage of the preliminary design of the product, the operating conditions are specified and the functions are described, the model of the product is formed exactly to its blocks, the production technologies of such products are designed in detail. At this stage of design, it is possible to use the following typical representations of the innovation object: intuitive (implicit knowledge), subject, functional-decomposition, service contours, aggregate-decomposition.

At the stage of the technical design of the product, all design documentation for this product and its production process are developed, tests of the product (product) are carried out in laboratory conditions. In this regard, at this stage (of the technical project), it is possible to use such typical representations of the innovation object in an innovative project: substantive, intuitive, functionaldecomposition, service contours, aggregative-decomposition, the "parameter tolerance field" model constructed using the behavior of product characteristics.

At the stage of prototypes, the manufactured prototype product is tested in fullscale (real, field) conditions. At the same time, the practical application of all the previously named representations is possible.

At the end of the 20th century, according to some expert estimates, the complexity of the stages of development of high-tech engineering products may be in the following proportions: the stage of the preliminary design and/or research work (R\&D) accounted for about $10 \%$ of all project costs; the stage of the preliminary design accounted for about $15 \%$ of all costs; the stage of the technical project spent $15-20 \%$ of all project funds; the stage of prototypes of the product accounted for $55-60 \%$ of the total cost of the project.

At the same time, it is recommended to remember that the level of risk in innovative projects in the field of high-tech engineering is higher than in the field of routine activities of organizations. This is confirmed by the information of Philip Kotler, indicating that $40 \%$ of all proposed innovations fail in the consumer goods market; $20 \%$ of all novelties fail in the industrial goods market, and about $18 \%$ of services fail in the services market [Kotler (1990), p. 288]. At the same time, the damage to the subject of innovation activity can be quite large. So it is known that on its unsuccessful model "Edzel", the Ford automobile company, according to expert estimates (in the 1950s), had damage of about \$ 350 million [Kotler (1990), pp. 289-290]. In addition, with the unsuccessful implementation of an innovative project, image damage also occurs. For a smaller enterprise, such financial and image damages could be catastrophic.

\section{CONCLUSION}

The article proposes a method for synthesizing ideas for innovative projects during the development of the ETO. It is shown that the theory of technological orders helps to synthesize the ideas of innovative projects. Such projects should be aimed at introducing new technologies into the products and production capacities of existing enterprises. The article describes the stages of synthesis of innovative ideas, offers tables for analyzing the effectiveness of innovative ideas. The results of 
such analysis, as well as research and modeling of business projects should be used in the preparation of business plans for innovative projects. The article presents the following results: approaches to the synthesis of ideas of innovative projects are described; methods of modeling business processes are investigated; the process of drawing up a business plan for an innovative project is studied and described. The results of this article will be useful in the practical implementation of innovative projects, taking into account the peculiarities of the processes of formation of the eighth technological order and more.

\section{REFERENCES}

Altshuller G.S. (1986) Find an idea. Introduction to the theory of inventive problem solving. - Novosibirsk: Nauka. -209 p.

Bandurina O.S. (2012) Ideas need business, and business needs ideas//Patent case. No. 1. pp. 7-10.

Borovik G.G., Doroshenko K.V. (2020) The concept of an ecosystem, types of ecosystems and the main differences between natural and anthropogenic ecosystems//Student Forum. No. 30 (123). pp. 23-24.

Glushchenko V. V. (2020) Scientific theory of teams and strategic management of team work // Bulletin of Science and Practice. Vol. 6. No. 4. pp. 272-287. Retrieved from https://doi.org/10.33619/2414-2948/53/32

Glushchenko V. V., Glushchenko I.I. (2000) Development of a management solution. Forecasting is planning. Theory of experimental design- Zheleznodorozhny, Moscow region, LLC NPC "Wings". -400 p. Ed. 2nd ispr.

Glushchenko V.V. (2020) Project model of functioning of the organizations// The scientific heritage, 2020, vol. 3, No. 53, p. 15- 33

Glushchenko V.V. (2006) Risks of innovation and investment activity in the context of globalization.- Zheleznodorozhny, Moscow region: LLC NPC Wings. - 230 p.

Glushchenko V.V. (2021) The structure of the mechanism of development of social and professional institutions of the new technological order//Kazakhstan Science Journal.. Vol. 4. No. 7 (32). pp. 22-39. Retrieved from https://sciencejournal.press/sj/article/view/264/216 (accessed: 07.07.2021)

Glushchenko V.V., Glushchenko I.I. (2015) Scientology: the task of modernizing science and innovation, - M.: Glushchenko Irina Ivanovna; $116 \mathrm{p}$.

Glushchenko V.V. (2021), Scientific theory of the service sector (servicology, service business) in the conditions of the sixth technological order. - M.: Glushchenko Valery Vladimirovich.- 116 p.

Glushchenko, V. V. (2021). Creating a model of the future of the eighth technological order. International Journal of Engineering Science Technologies, 5(5), 1740. Retrieved from https://doi.org/10.29121/ijoest.v5.i5.2021.217.

Glushchenko, V. V. (2021). The mission and essence of the theory of technological orders. International Journal of Engineering Science Technologies, 5(4), 6582. Retrieved from https://doi.org/10.29121/ijoest.v5.i4.2021.205.

Hikmatov H.H., Burieva S.Z. (2020) Formation of innovative ideas in students in laboratory and practical classes//Academy. No. 7 (58). pp. 19-21.

Howe, Neil; Strauss, William (2008). Millennials \& K-12 Schools (neopr.). LifeCourse Associates. - pp. 109-111.

Kotler F. (1990) Fundamentals of marketing. Translated from English/ General ed. and introduction by E.M. Penkova. - M.: Progress. - 736s. 
Kotler F. (1990) Fundamentals of marketing. Translated from English/ General ed. and introduction by E.M. Penkova. - M.: Progress,. - 736s.

Kovalchuk M.V. (2021) Nature-like (convergent) technologies - global threats and challenges//SPbPU Science Weeks, Peter the Great St. Petersburg Polytechnic University, https://www.youtube.com/user/SPBMEDIA .

Kurilova A.A. (2017) Procedure for conducting pre-investment analysis in the implementation of innovative projects//Karelian Scientific Journal. Vol. 6. No. 2 (19). pp. 99-103.

Litvinova A.G. (2020) The idea management system in the company in order to support and develop innovative activities//Global scientific potential. No. 6 (111). pp. 165-168.

Lukina O.A., Lebedeva T.E., Golubeva O.V. (2019) Methods of development and selection of innovative ideas at the enterprise//Moscow Economic Journal. No. 13. p. 54.

Maslyukovskaya A. (2013) The innovative theory of Joseph Schumpeter: from the classical definition of the concept of "innovation" to the modern understanding of innovative ideas//Bulletin of Taras Shevchenko National University of Kyiv. Economy. No. 145. pp. 59-61. Retrieved from https://doi.org/10.17721/1728-2667.2013/145-4/21

Sheve G., Khyuzig S., Shaimieva E.Sh., Gumerova G.I. (2021) Generation of innovative ideas: methods of bionics science in innovation management in the digital economy//In the collection: Scientific research: fundamental and applied aspects. Collection of scientific papers. Kazan, 2021. pp. 169-172.

Starodubova A. A. (2019) Methodology for generating innovative ideas through mentoring in entrepreneurship//Modern education: current issues and innovations. No. 4. pp. 263-267.

Straus S. (2005) Big idea, or how business inventors turned their ideas into a profitable product. trans. from the English V. Epimakhov. - Moscow, Grand.

Sychev V.A. (2018) System engineering - processes and standards//A young scientist.. No. 32 (218). pp. 17-22.

Workbook on forecasting (1982) / Editorial Board: I.V. Bestuzhev-Lada (ed.).-M.: Thought,.- $430 \mathrm{p}$. 